\title{
A Cryptography-Based System for Offline Collection and Verification of Tax Revenue by County Governments in Kenya
}

Nebert Mandala, (PhD Candidate, MBA, CPA[K], CISA, CPS[K])

University of Nairobi, Kenya

Carlton Wanga, (MSc.)

Strathmore University, Kenya

Prof. Josiah Aduda

School of Business, University of Nairobi, Kenya

Doi: 10.19044/esj.2017.v13n34p414 URL:http://dx.doi.org/10.19044/esj.2017.v13n34p414

\begin{abstract}
In the current setting of county governments in Kenya, efficient tax collection is highly dependent on validation of payment documents. This has led to challenges due to the fact that revenue collection has traditionally employed paper-based collection receipts. The research targets to address the challenges of validation of payment receipts in offline revenue collection systems. It supports automation attempts that have been made through the introduction of electronic mobile point of sale terminals. The solution is based on providing an offline model that supports the distributed nature of payment stations. This approach focuses on using cryptography-based techniques to enable offline validation of receipts even in cases of unreliable network connectivity. The objective is to provide a solution that affords ease of both revenue collections for the county governments and payments for the citizenry while stopping revenue leakages, ensuring reliable verification of payment receipts, thus maximising of revenue collection by providing reliable accounting reports. The research provides a reliable revenue collection system that enables offline receipting and verification of payment receipts in integrated mobile point of sale terminals. The solution presented has successfully been implemented and tested in one of the County Governments in Kenya.
\end{abstract}

Keywords: Tax collection, Receipt verification, Offline payment processing

\section{Introduction}

Kenya is currently under a decentralized system of governance whereby political, administrative and financial authority has been 
transferred from the national level to independent sub-national level units known as counties. The Kenyan Constitution 2010 created 47 counties whose operations are funded from both the national consolidated fund and collection of revenue from their own local sources. Revenue collection mainly comprise parking fees, business permits, land rates and other service fees such as local health facility payments. The constitution bars the counties from collecting formal taxes, which are collected by the national government through a collection agency, the Kenya Revenue Authority. Collection of revenue in county governments involves setting up collection stations that provide a means of receiving payments for defined revenue streams (Nduda, 2015). Upon receipt of service fees, collectors need to offer tickets or permits showing proof of payment. The collection receipts not only serve as proof of payment but also provide a way of verification before granting access to specific services (Nduda, 2015). Collection of parking fees is one of the most prominent modes of revenue collection. This process involves customers reserving parking slots by paying a fee. Parking attendants need to validate actual receipt of payment by verifying the payment ticket before allowing the vehicle to park in a specific area.

Devolution of revenue collection and management to the counties and subsequently to other administrative unites within the county comes with enormous challenges, especially lack of network and communication infrastructure needed to facilitate internet connectivity. There is, therefore, a need to employ alternative technologies that would enable offline collection and verification of revenue (Khaunya, Wawire, \& Chepng'eno, 2015).

Cryptography-based techniques have provided reliable methods for validation of electronic data (Alwyn \& Albertus, 2013; Christin \& SafaviNaini, 2014). The authentication capabilities made possible by public key cryptography using standard algorithms make it possible to develop robust data validation applications. The validation process is made conceivable by their ability to generate unique identifiers whose sequence of generation cannot be easily predicted. The techniques also make it possible to encrypt information blocks that can be decrypted by intended parties to enable viewing and validation of the actual data.

\section{Methodology and Hypothesis}

This study adopted a triangulated approach drawing both on primary and secondary qualitative and quantitative data. The study sought to draw from data sources from all the 47 counties. The data collected related to the own source revenue (OSR) and the study used descriptive and correlation analysis to draw a number of insights around automation and nonautomation. The primary focus was on the major innovations and best practices utilized to ensure efficiency in revenue collection using automated 
systems. Major challenges faced were also identified and analyzed together with the strategies used to address them. The findings focus on best practices and proffer policy and legislative recommendations on how to improve the capacity and performance of the revenue collection and management by County Governments.

The study hypothesizes that alternative automation technologies and models need to be developed based on the devolved two-level system of government whereby functions are either exclusive, concurrent or residual to either level thus requiring a complex infrastructure framework.

\section{Problem Statement}

Collection of revenue by county governments in Kenya has been plagued with numerous cases of fraudulent and counterfeit receipts that are used to avoid payment of fees (Ataro, Muturi, \& Wandera, 2016). In non-automated systems and some automated systems, verification teams have difficulties in differentiating between authentic and non-authentic receipts. This is because receipt validation would typically require a centralised database receipting system that can be queried to verify receipt of payment (Alwyn \& Albertus, 2013; Centeno, 2008). This is extremely difficult to achieve due to lack of reliable network connectivity across all stations of revenue collection. The problem is further fueled by the absence of a reliable tracking process or audit trails.

The consequence of poor revenue collection and payment validation structures is that County Governments are not able to meet their revenue collection targets. This is further compounded by the fact that it is very difficult to present a solid case against defaulters who do not pay service fees (Khaunya, Wawire, \& Chepng'eno, 2015). Individuals and small-scale enterprise engaged in economic activities also avoid payment of taxes to county governments due to the lack of a proper debt recovery mechanisms (Karori \& Abuga, 2016).

County Governments serve as the pillar of development and economic growth in Kenya today, and it is essential to ensure that they have the capacity to raise enough revenue to support development projects (Society for International Development, 2012; Buluma \& M.Obande, 2015). Cases of loss of revenue have been rampant since the inception of devolution. This is mainly due to poor revenue collection and receipt validation techniques (Nduda, 2015).

The Commission of Revenue Allocation Report (2015) also identifies lack of proper payment verification mechanism as one of the major challenges facing revenue collection by County Governments. The Commission of Revenue Allocation further issued a directive for counties to stop borrowing money to service their operations until they are able to prove 
their ability to pay debts based on their performance on local revenue collection.

However, counties are still suffering from unrecoverable debts due to poor record keeping as well as improper accounting procedures as a result of the use of paper-based receipt books (Ataro, Muturi, \& Wandera, 2016). It is estimated by the Commission of Revenue Allocation in it's 2015 annual report that county revenues are reduced by half due to revenue leakage as a result of inadequate procedures in the reconciliation of revenues collected and an over-reliance on erroneous paper documentation provided by revenue collection officers.

\section{Automation of Revenue by County Governments}

The primary objective of revenue automation by county governments is to enhance revenue collection and to ensure that service delivery to revenue payers is convenient and that it supports modern payment solutions. Convenient service delivery is that which avoids the need for taxpayers to have to go to authorities in order to access services of tax payment (Basu, 2010). The study sought to determine the effects of automation of revenue on the counties by analysing the amounts of revenue collected between the years 2013 to 2016.

Data on the total revenue collected by each of the 47 counties for the years 2013/2014, 2014/2015 and 2015/2016 was obtained. The years were relevant as this is when the counties were created and a number were in the process of automating. The counties were categorised into those that had automated the revenue collection and those that were still using manual processes. To analyze counties performance against the technological advances, a sample of 13 counties whose revenue collected processes were automated were selected by Simple Random Sampling (SRS) to compare with the performance of counties still using the manual system. Table 1 below provides the descriptive statistics of the revenue collected per county, the counties having been clastered into those with automated systems and those still using manual systems in revene collection. The results show that the Actual average OSR between periods 2013/2014, 2014/2015 and 2015/2016 are Kenya Shillings (KES) 583 million and KES 138.8 million for Automated and Manual based systems respectively. This shows that counties which have automated their revenue collection processes on average collected more revenue compared to the later; thus automated counties perform better as illustrated in graph plot 1.0 and graph plot 1.1 below. The maximum and the minimum Actual average OSRs for counties that have automated revenue collection systems and manual systems respectively are KES 1940 million, KES 330.7 million and KES 87.0 million, KES 31.0 million respectively. 
Table 1(a): Descriptive Statistics

\begin{tabular}{|c|r|r|r|r|r|r|r|r|r|r|}
\hline Variable & $\begin{array}{r}\text { Total } \\
\text { Count }\end{array}$ & $\mathrm{N}$ & $\begin{array}{r}\mathrm{N} \\
*\end{array}$ & $\begin{array}{r}\text { Cum } \\
\mathrm{N}\end{array}$ & $\%$ & $\begin{array}{r}\text { Cum } \\
\%\end{array}$ & $\begin{array}{r}\text { Me } \\
\text { an }\end{array}$ & $\begin{array}{r}\text { SE } \\
\text { Mean }\end{array}$ & $\begin{array}{r}\text { TrM } \\
\text { ean }\end{array}$ & StDev \\
\hline $\begin{array}{c}\text { Automated 2013- } \\
2016 \begin{array}{c}\text { Actual Average } \\
\text { OSR }\end{array}\end{array}$ & 13 & 13 & 0 & 13 & 100 & 100 & 583 & 159 & 505 & 575 \\
\hline $\begin{array}{c}\text { Manual 2013- } \\
\text { 2016 Actual Average } \\
\text { OSR }\end{array}$ & 13 & 13 & 0 & 13 & 100 & 100 & $\begin{array}{r}138 . \\
8\end{array}$ & 26.4 & 131. & 95.2 \\
2 & & & & & & \\
\hline
\end{tabular}

Table 1(b): Descriptive Statistics

\begin{tabular}{|c|c|c|c|c|c|c|c|c|}
\hline Variable & $\begin{array}{c}\text { Varianc } \\
\text { e }\end{array}$ & CoefVar & Sum & $\begin{array}{c}\text { Sum of } \\
\text { Squares }\end{array}$ & Min & Q1 & Median & Q3 \\
\hline $\begin{array}{c}\text { Automated 2013- } \\
\text { 2016 Actual Average } \\
\text { OSR }\end{array}$ & 330385 & 98.59 & 7579 & 8383563 & 87 & 143 & 406 & 662 \\
$\begin{array}{c}\text { Manual 2013-2016 Actual } \\
\text { Average OSR }\end{array}$ & 9065.5 & 68.60 & $\begin{array}{c}1804 . \\
3\end{array}$ & $\begin{array}{c}359218 . \\
1\end{array}$ & $\begin{array}{c}31 . \\
0\end{array}$ & $\begin{array}{c}84 . \\
7\end{array}$ & 101.7 & 205.0 \\
\hline
\end{tabular}

Table 1(c): Descriptive Statistics

\begin{tabular}{|c|r|r|r|r|r|r|r|r|}
\hline Variable & Max & Range & IQR & $\begin{array}{r}\text { Mod } \\
\mathrm{e}\end{array}$ & $\begin{array}{r}\text { N for } \\
\text { Mode }\end{array}$ & $\begin{array}{r}\text { Skewnes } \\
\text { s }\end{array}$ & Kurtosis & MSSD \\
\hline $\begin{array}{c}\text { Automated 2013- } \\
\text { 2016 Actual Average OSR }\end{array}$ & 1940 & 1853 & 520 & $*$ & 0 & 1.70 & 2.19 & 238854 \\
\hline $\begin{array}{c}\text { Manual 2013-2016 Actual } \\
\text { Average OSR }\end{array}$ & $\begin{array}{r}330 . \\
7\end{array}$ & 299.7 & $\begin{array}{r}120 . \\
3\end{array}$ & $*$ & 0 & 1.17 & 0.29 & 1283.3 \\
\hline
\end{tabular}

The study further carried out trend analysis on the data and the graph plot below presents the results. The revenue amounts collected by counties that have automated the revenue collection is ploted (in blue) against those that have not automated (in red). The results show that in almost all cases the counties that have automated performed better than those that have not automated their revenue collection systems. The y axis provides the amount of revenue collections in thousands of KES while the $\mathrm{x}$ axia is the counties sampled having been numbered from 1 to 13 . To further establish whether a relationship exists between the collections by those counties that have automated their revenue collectiion systems and those that have not automated, the study carried out correlation analysis. The results below show a correlation coefficient of 0.11 ; it does not show much of anything between the two given that it is close to 0 . 


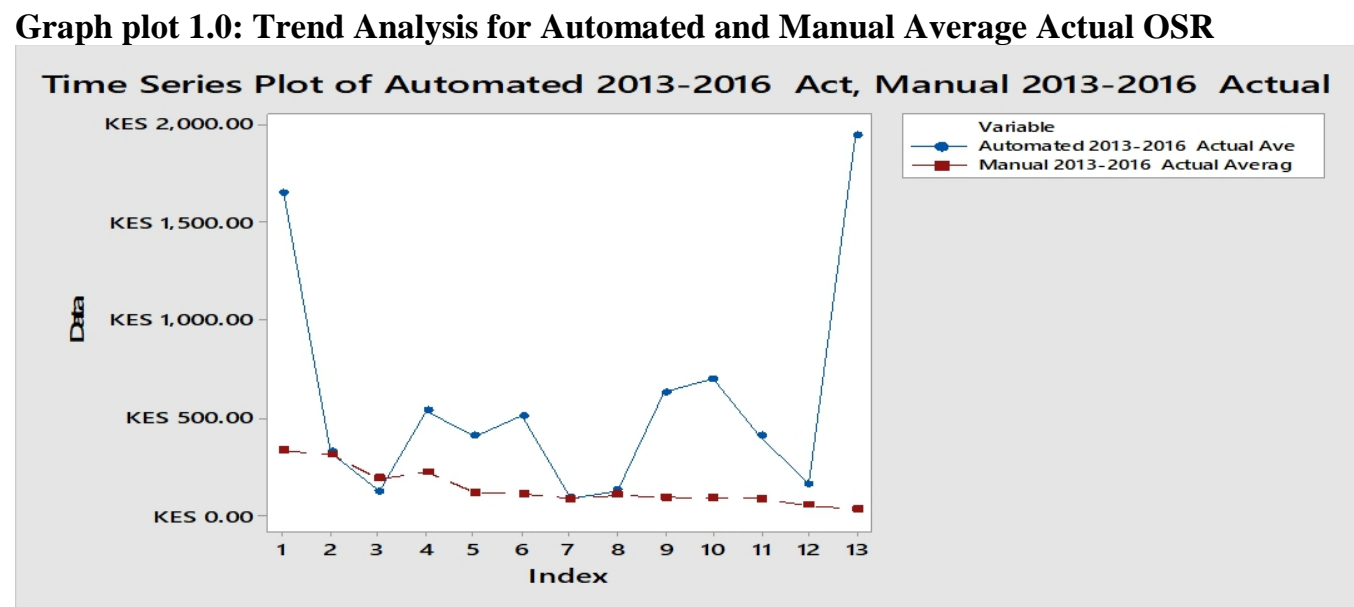

Fitted Trend Equation

$\mathrm{Yt}=481+14.5 \times \mathrm{t}$

\section{Correlations}

\begin{tabular}{|c|c|}
\hline Pearson correlation & 0.114 \\
\hline P-value & 0.711 \\
\hline
\end{tabular}

\section{Challenges Facing Automation of Revenue Collection}

The results indicate that the counties should adopt automation of revenue collection systems in order to enhance revenue collection. This is in line with the Commission on Revenue Allocation (CRA) that advised, there is an urgent need for county governments to automate the revenue collection process in order to seal the gaps that cause revenue leakages (Commision of Revenue Allocation, 2015). It is important to note that counties are however, still facing massive network connectivity challenges that hamper the automation process. It is, therefore, imperative that alternate automated solutions that can robustly handle connectivity challenges are developed.

Network connectivity problems could be solved by developing offline mobile application solutions. However, an integrated revenue management system requires a mechanism to perform verification checks such as validation of parking receipts. It would otherwise be very difficult to carry out such verifications without some form of network communication (Mburugu, 2016).

The infrastructure required to handle the demands of the traditional paper-based way of revenue collection is also costly to set up and cumbersome to maintain (Ngotho \& Kerongo, 2016; Mutysia, 2014). Despite the technological potential that can be released by leveraging on the power of the internet to improve revenue growth in County Governments, most of the 
areas are remote, and the network coverage in most instances unreliable (Nduda, 2015).

\section{Internet Connectivity Challenges}

African countries still face challenges due to lack of reliable internet connection required to sustain governance and commercial activities. This poses a significant challenge as governments need to harness the power of information technology to provide better and convenient services (Ataro, Muturi, \& Wandera, 2016).

Lack of reliable internet connection is the root cause of lack of plausible advancements in development (Souter \& Kerretts, 2012). Internet connectivity challenges have to be overcome in order to achieve greater public access to information that would make a distinctive, positive contribution to the democratic and socio-economic future of the continent (Diallo \& Calland, 2013).

Evidently, inadequate internet connectivity is a great challenge facing implementation of information systems in Kenya. There is therefore a great need to come up with alternate solutions that can overcome impediments caused by poor connection.

\section{Need to Implement Offline Capabilities in Financial Systems}

The greatest impediment to implementing systems which involve validation of payments is network communication (Lee, 2009). While current technological advances can comfortably provide reliable offline systems with data synchronisation capabilities, it becomes very difficult to confirm payments by verifying receipts when not all the data has been synchronised. In County Governments' revenue collection, it is important that an enforcement team is placed at strategic points to verify the validity of receipts. In cases of revenue collection on streams such as parking fees, there is a need for validation of vehicle number plates against a database of payments through verification checks to maximise on collection (Mutysia, 2014).

\section{Impacts of Revenue Automation}

Automation of revenue management mainly involves transition of revenue collection from the use of paper-based receipts to some form of electronic system that facilitates data entry, processing and reporting of revenue (Mutysia, 2014). The possible solutions vary from USSD wallets to self-service portals. The important aspect of automation is ensuring that convenient and effective service delivery is availed to customers while at the same time provide an effective monitoring and control structure that will avoid revenue leakage (Muthama, 2013). 
Automation not only makes it possible for accurate data capturing but also provides constraints to ensure that taxpayers are charged the correct amount that is defined on the finance bills. The power of network connectivity and computational storage makes it possible to integrate various applications to provide accurate reports (Mutysia, 2014).

In Kenya, automation is a result of tax administration reforms to better improve the reporting of revenue (Muthama, 2013). It has been common for counties to give understatements of revenue they collected or sometimes fail to account for the revenue performance (Commision of Revenue Allocation, 2015). Keeping track of all revenue streams has been faulty. With inaccurate data, it has not been possible for counties to do predictive analysis or effective planning (Mutysia, 2014). This is, therefore, a key challenge that affects Kenya as a country at large and needs improvements so as to foster development.

\section{Models, Techniques and Technologies for Improvement of Revenue Collection}

Receipting is an unavoidable component of every revenue collection system. The need for printing is inevitable in most payment solutions. Electronic Tax Register (ETR) receipts have served an important role in servicing payments in most developing countries (Lumumba, 2010). Efficient collection of revenue requires mobile capabilities that can enable provision of services in any location even those where setting up of physical computers can be a challenge (Omwansa, 2014). Electronic receipting offers many advantages over paper-based receipting by providing a mechanism for efficient record keeping as well as well as effective reporting (Lumumba, 2010). This provides the advantage of non-repudiation where the service clerk and the customer cannot deny processing of a particular transaction (Lumumba, 2010).

Effective mobile payments should ensure that the synchronised figures are correct and that it can be guaranteed that the transaction details have not been modified. Important narration details should be captured as well as corresponding audit trails to ensure that both parties can be identified so as to guarantee transparency. Mobile transactions also need restricted access and security mechanisms to ensure that the receipts are accessible only to those who are authorised to view the corresponding transactions (ISACA, 2011).

The primary objective of a point of sale terminal services is not only to guarantee reliable electronic transactions of billing and receipting payment, but also to ensure that communication between cashiers, managers administrators and other stakeholders is easier and more reliable as compared to the physical receipting. Due to the possibilities of user authentication and 
authorisation brought about by the computational abilities of mobile point of sale terminals, it can be guaranteed that transactions have been performed by users who have actually been authorised to perform those operations (ISACA, 2011).

\section{Mobile Point of Sale Terminals}

Ecommerce and retailing operations have been revolutionised by the advent of mobile point of sale terminals (Godbole, 2006). Mobile point of sale devices have the ability to support development of custom payment solutions since they are embedded with smart operating systems and powerful software development kits (Sharma, 2016). According to Sharma, these devices provide a great potential for additional access services. This is because, operating systems such as android provide additional sensory capabilities such as geolocation which can serve as an important tool to obtaining accurate transaction location for control mechanisms as well as provide reliable geolocation reports (Tanai, 2014).

In additional to geolocation capabilities, mobile point of sale terminals are built with revolutionary device capabilities that are not available in conventional computers. Use of payment cards has become a convention in the processing of mobile payments (Jih, 2009). Most mobile point of sale terminals come prebuilt with readers that can read both magnetic and smart cards making it possible to process payments through swiping of cards or tap as you go services (Yamamoto, 2012). Since mobile terminals are built with smart phone technologies, they offer tools such as RFID, and QR code scanners that can be used to perform verification checks.

If well designed applications running on mobile point of sale terminals can be well designed to handle offline data storage and supported by their abilities of cellular connections as well as $\mathrm{Wi}-\mathrm{Fi}$ to handle data synchronisation with offline servers (István, 2008). Modern terminals also have out of the box data storage capabilities that makes it easy to perform caching of data dictionaries as well as application preferences. Apart from the portability that is brought about by using mobile terminals, they also come with inbuilt thermal printers that can meet all receipt issuance needs.

These devices have already been employed in other sectors such as shipping deliveries. If well utilised these devices can serve as effective point of sale devices for revenue collection. Figure 1 shows a mobile point of sale terminal with an in-built thermal printer. The device is powered by Android and provides the ability to print receipts as well as read bar codes. 


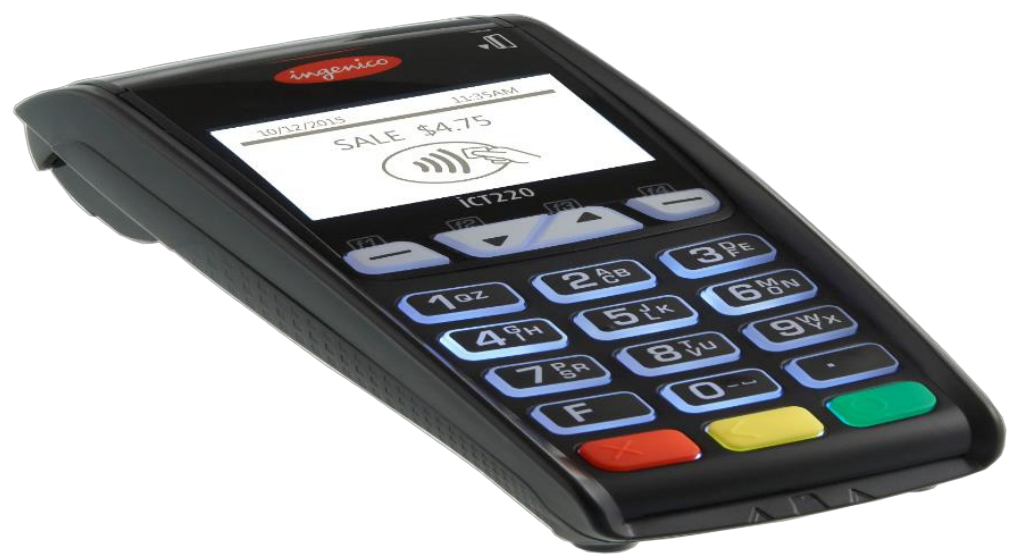

Figure 1: Point of Sale Terminal with a Thermal Printer (Adapted from Deloitte, 2017)

\section{Receipting with Bluetooth Thermal Printers}

Bluetooth thermal printers are a new technology that have made it possible to process payments through the use of conventional mobile phones (István, 2008). They serve as an add-on that provides the possibility to print directly from mobile phones thereby leveraging on the computational abilities of smart phones (Leonardo, Beniamino, \& Marcello, 2014). Figure 2 shows a Bluetooth thermal printer. These devices are light weight, have a long battery life and also offer high printing speeds of around $60 \mathrm{~mm} / \mathrm{s}(480$ dots/sec).

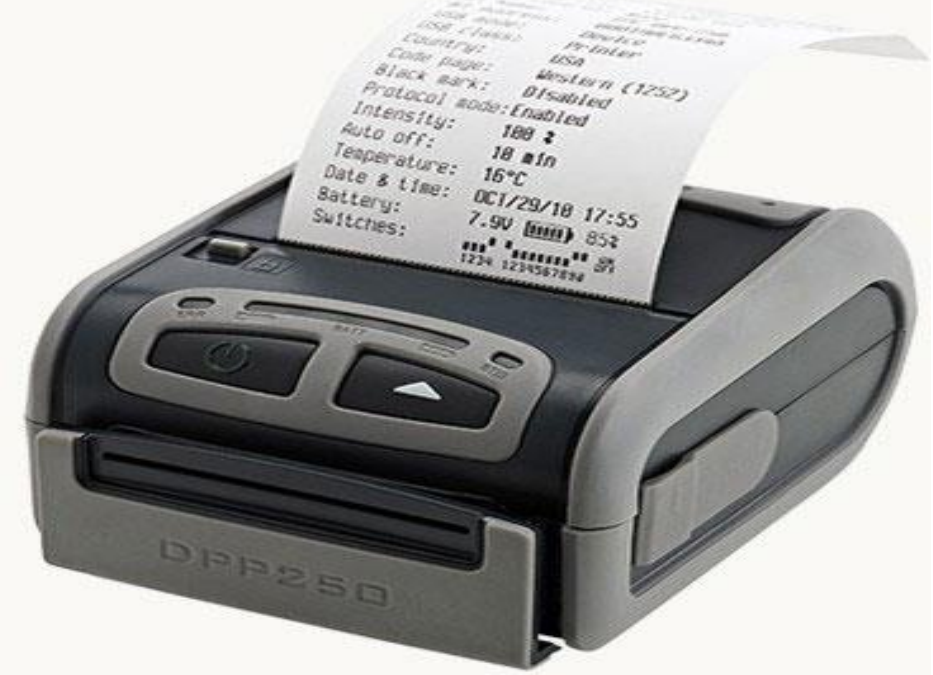

Figure 2: Bluetooth Thermal Printer (Adapted from Datecs, 2017) 


\section{Verification and Validation of Receipts}

Automation of revenue has proven to be a great success in improving revenue collection in a number of counties (Mutysia, 2014; Khaunya, Wawire, \& Chepng'eno, 2015). However, there has still been an inevitable challenge of being able to validate authentic payments and to detect the validity of payment receipts. Typical validation procedures involve some sort of network communication that transmits payment narrations such as the receipt number to a remote server that servers the purpose of validating the receipt against payment records (Raina, 2014).

While the approach of remote database checks can be effective in areas where network connectivity is guaranteed, the county environments offer a more unfriendly environment where network connectivity for the verification process is not always guaranteed (Adera \& Waema, 2011). In addition, the collection centres might not have synched all transactions by the time verification is required. Even with presence of stable network connectivity validating some revenue such as parking fees can pose a challenge since the time of validation might not be enough to accommodate the network request-response life cycle for example when the vehicle in question is being driven.

In an offline system, there are also many challenges that come about which might affect the generation of unique receipt numbers (Johri, 2008; Christin \& Safavi-Naini, 2014). Conventional receipting involves using a sequential auto increment key in the database to easily generate distinct receipt numbers. In cases of multiple offline device terminals, there is risk of collision of the serial identity keys since every device has a different offline database (Johri, 2008). To ensure uniqueness of fields from various offline databases that are synchronised to a central database connection hash algorithms can be used with the input function using the unique identification details of the offline databases to generate unique records.

Offline verification in practice can also be achieved by the use of cryptography (Pedro, 2015). In Kenya, this has implemented in the prepayment electricity meter system, which uses tokens to identify the value and authenticity of purchased tokens without network communications to verify that the payment was actually made.

\section{QR Codes for Receipt Verification}

The issue of receipt verification is also still challenged by the possible length of receipt numbers that may require typing into a verification system. If the receipt number is as a result of a cryptographic function, this could be a very long string that could take a lot of time to input (Simon, 2013). There is need to have some form of optical recognition system to the process of data input easy. QR code have the advantage of being able to store huge 
amounts of information. QR codes are versatile and can accommodate information of this nature (Raina, 2014).

\section{Implementation}

The research developed a system that targets to enable offline collection of revenue and verification of receipts in integrated point of sale terminals. It consists of two main applications with the main one running on the android platform and supported by a web based application. This system has been successfly been implemented by the County Government of Bungoma.

\section{System Design}

The system design model comprises of mobile point of sale collection devices that are connected to a Bluetooth thermal printer. These collection devices have the ability to work offline. They serve as cashier units that receive payment from customers. Once collection transactions have been processed a data synchronization process is initiated. This process involves sending transactional data to a central web server over HTTPS. The central server is connected to a number of service components that contain monitoring and data storage sub systems. Web client applications then provide real time reporting provisions through email and SMS notification channels.

\section{Programming Tools Details}

This section outlines the tools that were used in the development phase of the system. It provides an overview of the software development practices that were followed. The section also provides a description of the technologies that helped in the development of the system.

Database

The web based database was implemented using the PostgreSQL database application server. This is mainly because it provides better query processing performance as compared to other open source alternatives such as MySQL. To enhance data integrity, fields such as receipt numbers that need to be unique also have database constraints to ensure uniqueness.

Mobile Application

The mobile application was implemented using the native android development kit. It provides an interface that enables collectors to receive payment. The application offers capabilities that enable printing of receipts. Receipt generation is automatically supported when the user is using a device with an inbuilt thermal printer. However, in cases where the user is using a mobile phone the application also has support for receipt printing on a bluetooth printer. The most important aspect of the mobile application is 
that it is able to perform the two main functions of receipting and receipt verification when it is offline. The application therefore has an internal storage engine developed using a SQLite database.

Data synchronisation in the mobile application is achieved through a sync manager that automatically detects when the device is offline to synchronise all transactions that have not been committed to the central database. Users also have the ability to set application preferences on how often they would like the device to attempt synchronisation with the web application.

\section{Web Application}

The web application is implemented using Java. It follows object oriented design patterns to structure the low-level functions. The application is designed to be accessed on any web browser. The web application runs on a tomcat server. The application design also follows the MVC pattern to enable better code reuse. The back end is also composed of a restful web service that interacts with the mobile application. The web service uses JSON data format to enable communication with third parties.

\section{Implementation Details}

This section provides details of how various system processes were developed to enable the application meet functional requirements. The section provides an overview of concepts that were followed during the development phase and the thinking behind the system's implementation details. Table 1 illustrates technical components of the proposed system.

Table 1 : Technical System Components

\begin{tabular}{|l|l|}
\hline Application server for the backend & Apache Tomcat \\
\hline Database server & PostgreSQL \\
\hline Hosting Environment & Google Cloud \\
\hline $\begin{array}{l}\text { Point of Sale Terminals Operating } \\
\text { System }\end{array}$ & Android \\
\hline Server Operating system & Debian \\
\hline Language and framework & $\begin{array}{l}\text { JDK 1.8, J2EE, Spring Framework, } \\
\text { Groovy, JPA }\end{array}$ \\
\hline Reporting component & Jasper Report \\
\hline
\end{tabular}

\section{Cryptographic Offline Verification}

The system achieves the main objective of enabling offline verification of receipts by using cryptographic tokens. This is achieved using a cryptographic algorithm that takes important fields of a transaction which are the date, narration and amount collected to generate a receipt number upon receipt of payment. The algorithm ensures that the generated receipt numbers do not follow a generated sequence but instead are a random 
combination of unreadable text. All linked point of sale terminals have a shared key that is able to decipher the receipt number generated by other point of sale terminals.

It was essential to ensure that the generated receipt number tokens have a unique identifying token and that the identifier was human friendly in terms of length and character encoding. To make this possible, the research used Base 32 encoding specified in RFC 4648. The encoding would ensure that; the overall length of the token is reduced since it applies compact encoding and also avoid similar looking characters therefore minimising transcription errors. This is for example achieved by avoiding the use of the number one due its similarity with the letter I as well as Zero due it its resemblance to the letter $\mathrm{O}$. The table below shows the base 32 character set that was employed.

\begin{tabular}{|l|l|l|l|}
\hline A & B & C & D \\
\hline E & F & G & H \\
\hline I & J & K & L \\
\hline M & N & O & P \\
\hline Q & R & S & T \\
\hline U & V & W & X \\
\hline Y & Z & 2 & 3 \\
\hline 4 & 5 & 6 & 7 \\
\hline$=$ & & & \\
\hline
\end{tabular}
algorithm.

The application generates Base 32 identifiers using the following

i. The number of IDs to last the application accounting cycle is estimated using an 8 bytes long integer which was selected as $2^{\wedge} 64$. This served as the database key column.

ii. A secure random generator is used to ensure the receipt numbers are unpredictable in this case the java class java.security.SecureRandom.

iii. Upon receipt generation, the ID is run through a base 32 encoder.

The following are the results that were achieved by using base 32 encoding over the standard UUID:

UUID (Standard format): 38503690-0475-4c48-95ed-a3c9eaa2ac3a UUID (Base 32): HBIDNEAEOVGERFPNUPE6VIVMHI

The application uses digital signatures as the preferred encryption algorithm. This is because digital signatures provide integrity, authentication and non-repudiation which meet the required specification for the encryption algorithm needed to generate a unique identifiable receipt number token. Digital signatures were preferred over hash-based message authentication code (HMAC) because they offer non-repudiation which was important in 
the receipting processes to ensure that collectors take responsibility for all transactions.

The research settled on use of RSA over elliptic curve algorithm because RSA offers a broader support in terms of programming libraries available. RSA256 was preferred because it is based on RSA PKCS \# 1 which is the most widely used private/public key cryptographic technique. The signature also requires minimal CPU time to perform a verification check and would therefore be most appropriate for mobile devices.

Validation is achieved by a counter algorithm that is able to decipher the cyphertext using a secret key. If it is not able to decipher the receipt number using the agreed key then that receipt number will be flagged as invalid. The validity of the payment is confirmed after the receipt number has been decrypted to obtain the date of payment, amount and narration details of the transaction. Since the algorithm generates long receipt numbers that may be quite difficult to manual input into a search field, the token is represented using a QR code that is scanned during the verification stage. The verification engine then attempts to use the secret key to obtain transaction details and displays corresponding results.

\section{Data Synchronization}

Data synchronization in the system is achieved by maintaining two databases. A central database on a server that is responsible for holding all charge configurations and client databases that hold temporary payment data. Once a collector logs in to the application, a background service sends a HTTP data check request with the current timestamp as a request parameter. If there is need for synchronization the web service will return a JSON array containing data dictionaries that will then be parsed by the application to generate database insertion queries to save the newly downloaded data dictionaries.

Upon collection, the collection data is saved on a SQLite database on the device and marked with a flag to show that it has not been synchronized. The application contains a sync adapter that checks whether the internet connection is available. If the internet connection is determined to be available the application will select all data records in the SQLite database that have not synchronized and send a corresponding HTTP request to the server with the payment details as the request body. The server then saves all the corresponding transactions and returns a success message.

\section{Merits of the Cryptography Based Sytem}

i. The application has the ability withstand network connectivity problems because of its ability to work offline. 
ii. The system curbs the problem of prevalent use of counterfeit receipts by providing a robust receipt verification model.

iii. The application provides an electronic way of printing payment receipts making it easier to track collections.

iv. The system provides access to informative reports thereby making it easy for county officers to monitor collections.

\section{Limitations of the Cryptography Based Sytem}

i. Some operations such as initial user authentication and data caching require internet connection.

ii. Currently the solution is limited to running in point of sale terminals with the android platform.

iii. Verification receipt numbers are relatively long making verification input by typing hectic. The limitation was however overcome by using QR codes to make verification inputs easier to scan.

\section{Research Findings}

Automation of revenue collection and management is an important aspect of county government operations. The process is important in ensuring that counties are able to raise enough revenues to support their development agendas. To tap on the full revenue potential of county government, it is critical to ensure that the process adopts the best technologies. Having an electronic form of revenue collection will be very helpful in sealing revenue leakages. This is because it will provide a way of ensuring customers are correctly charged the appropriate fees. It is also clear that the current paper based process is not adequate to keep records for accounting purposes.

Reporting is an important aspect to ensure good governance, transparency and accountability. Lack of proper reporting has greatly affected revenue growth in county governments. This is because there is no way of properly monitoring collectors and tracking their collection operations to ensure that every process is done in accordance to the laid down procedure and with high integrity. Having a digital means of receipting and managing revenue collection will be helpful in solving the challenges some counties face. This is because it will provide a reliable way of ensuring that officers are able to access reports and take corrective actions on collectors that do not meet their collection targets.

Despite the great improvement that can be realised by providing an electronic form of revenue collection, the challenges of its implementation cannot be underestimated. The first challenge that needs to be overcome is the provision of a mobile way of printing receipts. This is brought about by the fact that revenue collection requires a high degree of mobility. Printing of 
receipts would typically require a stand by form of electrical power to run the printer. The research has however provided alternative approaches that can provide a mechanism of printing digital receipts on mobile devices through bluetooth printing gadgets that have a long battery life and are highly portable.

Solving the problem of mobile receipt generation to provide a digital receipt does not provide a solution to the challenge of providing monitoring capabilities of the collection process. Monitoring can only be realised by having system components that provide reliable reports. The reporting components can only be realised by providing a means of sending collection data to a central location. Network communication in the current setting is however a great challenge. Not all places of revenue collection have enough network coverage to support real-time network communication. In addition, communication is challenged by the fact that the receipting duration needs to be as short as possible and making network connections greatly affects the service time.

Offline collection is a challenging process. It is complicated by the fact that in cases of revenue collection, multiple devices are expected to store data that is ultimately expected to be mapped to a central database while ensuring that the integrity of the data is not compromised. It is also important to ensure that the unique record identifiers on local device databases do not conflict. In cases of financial systems such as receipting the generated receipt numbers should not only be unique but also unpredictable. The algorithm of receipt generation should have way of generating identification tokens that are not predicable and are also unique.

The research settled on the use of device serial numbers along with autoincremented database sequence as part of table primary keys to ensure uniqueness when data is synchronised. This can be a reliable way of design databases for offline mobile applications that need to synchronise with a central database server.

An offline application with syncing abilities would also require a way of storage of data dictionaries that have a direct mapping to the central database. The research adopted an approach of developing local data tables for data dictionaries. The dictionaries are subsequently updated by the client performing polling operations to check for any updates on the server side and updating the local data store. It is also critical to provide a mechanism of recording both the device's collection timestamp as well as the time when the transaction has synchronised with the main backend.

Another challenge to implementation of an offline collection model was the issue of managing data after synchronisation. The first approach would be to delete each record after it has successfully been synchronised with the server records. However, this would be an impediment to 
performing rollbacks. The research thereby adopted a mechanism of marking fields in the local device databases as synchronised after the synchronisation process. To ensure that the device is not affected by memory constrains the application automatically archives records at the end of the month where they are purged after one financial year.

\section{Conclusion}

Effective tax collection is a very important aspect of county government operations. It is evident that there are so many challenges facing the current paper based way of tax collection. The main challenge being that most of the money collected is not paidback to the county because loopholes enable revenue collectors to pocket a great share of the amount collected. The greatest solution to the problem is implementation of an electronic way of revenue collection.

The research showed that the current network infrastructural development status of county governments is not stable enough to support real-time receipting that involves server side communication. This is because network coverage is not always available. In addition, the time taken to post transaction details to a server side application will greatly delay the transaction time.

Offline receipting and receipt verification would greatly improve the process of tax collection since it solves the major challenges facing revenue collection in county governments. Implementing the solution will therefore improve the amount of money that is currently being collected and in the long run empower counties to promote development.

An offline revenue automation model is a new concept that also provides a number of implementation challenges. The research has identified a number of solutionss that can greatly enhance automation of revenue collection and at the same time function in other application arears that require payments and receiving of payments. The algorithms and models used in the development of the system are not limited to the use case of revenue automation. The same model can also apply in other industries such as shipping and delivery, hotel bookings and payments of event tickets.

Due to the many advantages that come with electronic receipting the study recommends that this application is adopted by sectors that have dispersed fields that handle processing of payments. If more research is put into improving the algorithms that make it possible to perform offline validation of receipts, the technology offers great potential in improving sales and the overall customer experience when making payments.

Use of the mobile point of sale also facilitates the adoption of cashless payment methods as a way of complementing offline receipting to provide customers with more payment alternatives. Cashless payments 
would also minimise cash handling by revenue staff thereby reducing cases of mishandling of money by revenue collectors.

\section{References:}

1. Adera, E. O., \& Waema, T. M. (2011). Local governance and ICTs in Africa. Cape Town, South Africa: Pambazuka Press.

2. Alwyn, H., \& Albertus, P. (2013). Securing Number plates based on Digital Signatures and RFID. 21-27.

3. Ataro, P. O., Muturi, W., \& Wandera, W. R. (2016). Factors Affecting Revenue Collection Efficiency in County Governments in Kenya. A Case Study of Trans-Nzoia County.

4. Basu, S. (2010). Possibility and Desirability. Direct Taxation and ECommerce, 37-63.

5. Buluma, F. C., \& M.Obande, M. N. (2015). Justification for a Devolved Systems of Government: Corporate Governance and Financial Management Issues in Kenya.

6. Centeno, C. (2008). Securing Internet payments the potential of public key cryptography, public key infrastructure and digital signatures.

7. Christin, N., \& Safavi-Naini, R. (2014). Financial Cryptography and Data Security. 18th International Conference. Berlin: Heidelberg.

8. Commision of Revenue Allocation. (2015). CRA 2015 Conference Action Points. Nairobi: Comission of Revenue Allocation.

9. Diallo, F., \& Calland, R. (2013). Access to information in Africa : law, culture and practice. Leiden.

10. Godbole, N. (2006). Relating Mobile Computing to Mobile Commerce.

11. ISACA. (2011). Mobile Payments. Risk, Security and Assurance Issues, 5-9.

12. István, M. (2008). New Challenges for Smart Organizations.

13. Jih, W.-J. K. (2009). Service Features, Customer Convenience, and Shopping Intention in the Context of Mobile Commerce.

14. Johri, A. (2008). Online, Offline, and In-Between.

15. Karori, N., \& Abuga, V. M. (2016). Influence of Revenue Colletion Efficiency on the Operational Performance of Kisii County Government, Kenya.

16. Khaunya, F. M., Wawire, P. B., \& Chepng'eno, V. (2015). Devolved Governance in Kenya. Is it a False Start in Democratic, 27-29.

17. Lee, I. (2009). Triangular Strategic Analysis for Hybrid E-Retailers. InfoSci-Books. 
18. Leonardo, C., Beniamino, D. M., \& Marcello, M. (2014). Smart organizations and smart artifacts : fostering interaction between people, technologies and processes. New York: Springer.

19. Lumumba, O. M. (2010). The Effectiveness of Electronic Tax Registers in processing of Value Added Tax Returns. AIBUMA Publishing, 45-46.

20. Mburugu, K. P. (2016). Determinants Influencing Revenue Collection on the performance of Kenya Revenue Authority.

21. Muthama, J. (2013). The Effects of Revenue System Modernization on Revenue Collection At Kenya Revenue Authority.

22. Mutysia, J. (2014). Effects of an Interfreated Revenue Management System and Challenges facing its Implementation in Machakos county .

23. Nduda, J. M. (2015). Analysis of Factors Influencing Optimal Revenue Collection By County Governments in Kenya.

24. Ngotho, J., \& Kerongo, F. (2016). Determinants of Revenue Collection in Developing Countries. Kenya's Tax Collection Perspective.

25. Omwansa, T. K. (2014). Introduction of VAT on ICT Equipment in Kenya. Special focus on Mobile Phones, 30-33.

26. Pedro, F. (2015). Understanding Bitcoin : Cryptography, Engineering and Economics. West Sussex: Wiley.

27. Raina, V. K. (2014). Overview of Mobile Payment.

28. Sharma, M. (2016). Services of Mobile Commerce.

29. Simon, M. G. (2013). Mobile-based verification in anti-counterfeit commodity supply chain management systems. 379-388.

30. Society for International Development. (2012). Public Finance Reforms in Kenya. Issue and Relevance Under the Context of Devolution, 12-16.

31. Tanai, K. (2014). Monetary and Capital Markets . Oversight Issues in Mobile Payments, 5-19.

32. Yamamoto, Y. (2012). Open Service Field-Point of Service. A Method to Continuously Observe Tourist Behavior in Sightseeing Areas, 86-98. 